\author{
Cadernos de \\ ESTUDOS LINGUUISTICOS - (59.1), Campinas, pp. 91-110 - jan./abr. 2017
}

\title{
O PAPEL DOS FRAMES NA ORGANIZAÇÃO DO TÓPICO DISCURSIVO E NA COESIVIDADE COMUNICACIONAL NA INTERAÇÃO ENTRE AFÁSICOS E NÃO AFÁSICOS
}

\author{
EDWIGES MARIA MORATO* \\ ERIK FERNANDO MILETTA MARTINS** \\ NATÁLIA LUÍSA FERRARI ${ }^{* * *}$ \\ RAFAELA DEFENDI MARIANO $* * * *$ \\ RAFAHEL JEAN PARINTINS LIMA*****
}

\begin{abstract}
RESUMO: Postulamos em nosso estudo que modelos cognitivos de tamanho e escopo diferentes, como contextos mentais e frames, base do envolvimento e do enquadramento das interpretações levadas a cabo pelos indivíduos em interação, funcionariam como face sociocognitiva da referência. Em outros termos, enquadres sociocognitivos são tão importantes quanto as expressões referenciais para a manutenção, a continuidade e a gestão do tópico, bem como para a coerência discursiva e a coesividade comunicacional. As perguntas teóricas que nortearam nosso estudo foram: (i) como a instauração e a mobilização de frames (re)organizam o desenvolvimento do tópico discursivo? (ii) como os frames atuam na construção da referenciação (sobretudo, mas não só) no contexto das afasias? Entre os resultados obtidos, ressaltamos que os interagentes afásicos e não afásicos realizam um percurso discursivo sociocognitivamente ancorado em construções referenciais, em processos de centração e de organicidade inter e intratópica, em frames localmente ativados e construídos.
\end{abstract}

Palavras-chave: frames; tópico discursivo; referenciação.

ABSTRACT: In this research, we postulate that cognitive models of different sizes and scopes, such as mental contexts and frames - basis for both interactional engagement and framing of interpretations undertook by individuals - work as the sociocognitive face of reference. In other words, sociocognitive frame(ing) hold the same importance as referring expressions for the discursive topic's maintenance, continuity and management, as well as for discursive coherence and communicative cohesion. The theoretical enquiry of this study comprehends questions as: (i) how do frame establishment and mobilization help (re)organize discursive topic development?; (ii) how do frames act in the construction of reference, mainly but not only, in the context of aphasia? Amongst results, we highlight that both aphasic and non-aphasic interactants accomplish a discursive path that is sociocognitively anchored

*Universidade Estadual de Campinas, Campinas (SP), Brasil. edwiges@iel.unicamp.br

** Universidade Federal do Rio Grande do Norte, Natal (RN), Brasil. erikmiletta@gmail.com

*** Universidade Estadual de Campinas (Pós-Graduanda em Linguística), Campinas (SP), Brasil.nataliaferrari328@gmail.com

**ake Universidade Estadual de Campinas (Pós-Graduanda em Linguística), Campinas (SP), Brasil.rafaeladefendi@gmail.com

${ }_{* * * * * *}^{*}$ Universidade Estadual de Campinas (Pós-Graduanda em Linguística), Campinas (SP), Brasil. rafahel.jean@gmail.com 
in: locally active and/or constructed frames; referential processes; inter- and intra-topic processes of organicity and centration.

Keywords: frame; discursive topic; referential processes.

\section{INTRODUÇÃO: O CONTEXTO INTERACIONAL FOCALIZADO}

Apresentamos e discutimos neste artigo os principais resultados de uma pesquisa ${ }^{1}$ cujo objetivo foi analisar o papel dos frames na organização do tópico discursivo em conversações desenvolvidas no Centro de Convivência de Afásicos (doravante, CCA), da Universidade Estadual de Campinas (UNICAMP).

O CCA é um espaço de convívio semanal entre pessoas afásicas e não afásicas, dedicado especialmente às práticas discursivas as mais diversas, às ações conjuntas (como a elaboração do "Jornal do CCA") e às oficinas de arte (como o Programa de Expressão Teatral). Desse grupo fazem parte indivíduos afásicos e não afásicos (pesquisadores, amigos e familiares) de diferentes faixas etárias, ocupações profissionais, graus de letramento, procedências, nacionalidades, perfis socioeconômicos, experiências psicossociais e accountabilities (MORATO, 2010a) $)^{2}$.

As afasias, resumidamente, são alterações de produção e compreensão da linguagem oral e/ou escrita que decorrem de lesões estruturais no Sistema Nervoso Central, causadas em geral por acidentes vasculares cerebrais, tumores e traumatismos cranioencefálicos. Podem ser associadas a sinais e sintomas neuropsicológicos como hemiplegias, apraxias e agnosias. Ainda que a afasia nem sempre signifique apenas desvio e excrescência em relação à produção linguística tida como normal, encontramos na fala (e na escrita) de afásicos um conjunto de processos neurolinguísticos, tais como dificuldade de encontrar palavras ou alterações gramaticais e prosódicas que afetam de várias formas a fluência verbal, a comunicação, a interação social.

Centrado no interesse pelas relações entre linguagem e cognição em uso, nosso estudo assumiu um compromisso teórico e analítico necessariamente interdisciplinar. Nesse sentido, articulamos na pesquisa contribuições advindas de distintas áreas de investigação, como os estudos textuais, sociocognitivos e neurolinguísticos.

Dos estudos neurolinguísticos evocamos os modelos não biomédicos das patologias linguístico-cognitivas, orientando-nos por um enfoque sociocognitivo e interacional da linguagem afásica (MORATO, 2012 [2001]). Dos estudos textuais, evocamos a noção cognitivo-discursiva de tópico (JUBRAN, 2006; MARCUSCHI, 2005, 2006; KOCH, 2004) e de referenciação (MARCUSCHI, 2001, 2005; KOCH, 2002, 2004). Evocamos, ainda, estudos que partem de uma

1 "Linguagem e cognição em interação - o papel dos frames na organização do tópico discursivo em conversações do Centro de Convivência de Afásicos (CCA-IEL/UNICAMP)" - Proc. Fapesp 2014/05850-5.

${ }^{2}$ Para maiores informações: http://cogites.iel.unicamp.br 
abordagem dinâmica e discursiva de frame (CROFT; CRUSE, 2004; CIENKI, 2007; VEREZA, 2013; MIRANDA; BERNARDO, 2013; MORATO, 2010b).

É, pois, em um contexto particular, o da interação que envolve pessoas afásicas, que procuramos observar como diferentes frames - uns mais estáveis do que outros - interatuam na construção referencial e no desenvolvimento do tópico discursivo, com foco nos fatos de linguagem e de outros processos semióticos (como a gestualidade, a expressão corporal, o direcionamento do olhar, a mímica facial etc.) e cognitivos (como os enquadres conceptuais e interacionais em jogo na situação, as atividades inferenciais, o compartilhamento de intenções, a atenção conjunta etc.).

O contexto das afasias permite, tanto por suas peculiaridades, quanto pelas analogias e comparações com processos linguístico-cognitivos não patológicos, teorizações mais abrangentes da linguagem e de processos a ela associados (JAKOBSON, 1981 [1954]). Vale notar, quanto a este ponto, que é ainda reduzido o número de estudos sistemáticos sobre o impacto da afasia na linguagem em uso, nos processos envolvidos na construção da referência ou nos enquadramentos sociocognitivos que atuam na construção do sentido. Assim, nosso trabalho inscreve-se em um tipo de abordagem do fenômeno linguístico-cognitivo de crescente interesse teórico e analítico.

Pelo que pode implicar em relação à compreensão das afasias, à diminuição do estigma sofrido pelo afásico e ao incremento de condutas terapêuticas pragmaticamente referenciadas, o estudo por nós empreendido investe-se também de relevância social.

\section{CONSTRUINDO AS HIPÓTESES DA PESQUISA}

Entre as operações verbais e não verbais responsáveis pela relação entre referentes e tópico discursivo, Marcuschi (2006, p.11) destaca as "operações de enquadre", a partir do que "uma determinada expressão pode evocar um conjunto de propriedades, relações ou associações (frames, cenários, esquemas etc.) ". No caso do tópico, afirma o autor, "certas organizações (configurações) que se manifestam em esquemas globais ou enquadres (frames)" se desenvolvem e se estabelecem no "encadeamento de elementos informacionais" (MARCUSCHI, 2006, p.10). Essa ponderação é tão mais importante quando sabemos que o tópico, por si mesmo, não garante a progressão referencial, apesar de fornecer condições favoráveis a ela (KOCH e MARCUSCHI, 1998; MARCUSCHI, 2006).

A questão que permanece ainda em aberto em relação à progressão tópica é: se os referentes não garantem a continuidade tópica, "como sabemos a que é que um falante se refere em dado momento do texto se não explicita linguisticamente (cotextualmente) o referente?"'(KOCH; MARCUSCHI, 1998, p. 169). Essa questão se torna ainda mais interessante quando pensamos nos processos referenciais de natureza menos explícita, que demandam a consideração de contextos e de inferências de naturezas diversas. 
Postulamos em nosso estudo que modelos cognitivos de tamanho e escopo diferentes, como contextos mentais e frames, base do envolvimento (no sentido que Goffman dá ao termo em seus estudos sobre o "ritual da interação", [cf. GOFFMAN, 1967]) e das interpretações levadas a cabo pelos interagentes, funcionariam como fonte sociocognitiva da referência. Em outros termos, enquadres sociocognitivos são tão importantes quanto as expressões referenciais para a manutenção, a continuidade e a gestão do tópico, bem como para a coerência discursiva e a coesividade comunicacional.

A forma como os indivíduos recategorizam, predicam e ancoram textualmente os referentes pode indicar algo sobre os conhecimentos organizados de suas experiências sociais: estes tanto evocam e "atualizam" frames (MORATO, 2010b; MORATO; BENTES, 2013), quanto podem indicar conexão entre eles (VEREZA, 2013).

A partir dessa ponderação, as perguntas teóricas que nortearam nosso estudo foram: (i) como a instauração e a mobilização de frames (re)organizam o desenvolvimento do tópico discursivo? (ii) como os frames atuam na construção da referenciação (sobretudo, mas não só) no contexto das afasias?

A dinâmica relação entre processos referenciais e frame se torna ainda mais interessante de ser observada quando os interlocutores têm frequentemente que se colocar de acordo em relação ao tópico conversacional em curso, ao sentido atribuído a um termo ou a um enunciado proferido pelo interlocutor, aos conhecimentos de várias ordens que devem ser ativados, fornecidos ou compartilhados na interação.

A fala off topic atribuída aos indivíduos afásicos é frequentemente associada às consequências que as dificuldades nominativas e gramaticais imprimem ao processamento linguístico. A desfocalização ou descontextualização tópica (KOCH; PENNA, 2006) atribuída à linguagem patológica (OVERMAN; GEOFFREY, 1987, apud HAMILTON, 1994) dar-se-ia tanto em função de uma alteração cognitiva (envolvendo os sistemas de memória, por exemplo), quanto em função de uma alteração metalinguística (envolvendo o acesso lexical, por exemplo). Em ambos os casos estariam em risco a continuidade referencial e tópica, a coerência discursiva e a coesividade comunicacional.

Contudo, como pudemos observar em nossos dados, longe de ser identificada apenas com uma carência metalinguística, a fala off topic explicita a interdependência entre atos de linguagem e contexto interacional e assinala o papel dos enquadres ou modelos sociocognitivos nos processos de significação verbais e não verbais.

Admitida essa consideração inicial, procuramos desenvolver, com base na observação do nosso corpus, extraído do AphasiAcervus ${ }^{3}$, hipóteses teóricas mais específicas acerca da inter-relação entre frames e processo referenciais na

${ }^{3} \mathrm{O}$ AphasiAcervus constitui-se de um registro audiovisual dos encontros semanais do CCA com vistas à compreensão e ao acompanhamento das atividades ali desenvolvidas (evocação e elaboração de práticas sociais relevantes para o grupo, potencialmente inclusivas e significativas). Constitui-se, pois, de práticas discursivas cotidianas. Para maiores informações: http://cogites.iel.unicamp.br/p/ aphasiacervus.html 
progressão tópica. São elas: (i) os frames atuam como face sociocognitiva da referência, textual e pragmaticamente concebida; (ii) os frames funcionam como uma indexicalidade sociocognitiva no desenvolvimento do tópico discursivo; (iii) os frames atuam na progressão tópica e esta atua na ativação e mobilização de frames por meio de processos referenciais e sociocognitivos tais como (re) categorização, inferenciação, reconhecimento de intencionalidade, common ground $^{4}$, perspectivação conceitual; (iv) em relação a seus papéis na progressão tópica e na coesividade interacional, os frames parecem atuar como âncoras sociocognitivas $^{5}$ mais externas e os processos referenciais como âncoras mais internas (SCHWARZ, 2000; KAMP, 2011).

\section{FRAMES E PROGRESSÃO TÓPICA: ELEMENTOS DE CONTEXTUALIZAÇÃO E COESIVIDADE COMUNICACIONAL}

A concepção de tópico que assumimos no escopo da pesquisa é aquela que o compreende como "um conjunto de referentes explícitos ou inferíveis concernentes entre si e em relevância num determinado ponto da mensagem" (JUBRAN et al., 1992, p. 361). Ou seja, não apenas as marcas linguísticas atuantes na coerência determinam a importância fundamental do tópico na organização do texto falado; também o faz a relação entre os referentes textuais e a perspectiva dos interagentes. Com isso, a relação entre tópico e sua base referencial será sempre contextualizada, uma vez que os elementos que compõem a situação comunicativa ou a prática discursiva, mobilizados pelos interagentes, serão aqueles considerados relevantes para a construção do sentido.

Contexto e tópico são, pois, construtos sociocognitivos derivados do trabalho interpretativo dos interagentes (VAN DIJK, 2012 [2008]; MARCUSCHI, 2005, 2006) $)^{6}$. Assim, o tópico também se revela como crucial na organização e no

${ }^{4}$ A noção de common ground tem se mostrado, de fato, relevante para entendermos melhor questões de compreensão, reconhecimento e compartilha de intenção, sistemas de crenças, práticas identitárias, várias formas de coordenação, de colaboração ou cooperação entre as pessoas. Essa noção, importante para as abordagens pragmáticas, sociolinguísticas e sociocognitivas, parece-nos crucial no empreendimento analítico de corpus, pois ajuda a identificarmos os conhecimentos compartilhados pelos membros do CCA e os efeitos de contextualização provocados pelas informações novas que surgem no decurso da interação.

${ }^{5}$ A noção de âncora para tratar da compreensão e da interpretação de objetos textuais e sociocognitivos pode ser válida, ainda, para dizer que frames, assim como referentes, não têm uma ontologia (específica). Serve para explicar que os sentidos estritos ou dicotomizados de um e de outro conceito (frame e referência), como em determinadas abordagens lógico-linguísticas, de fato, não se sustentam. Nem o primeiro está solto num mundo extralinguístico, nem o segundo está preso a uma metalinguagem especular do mundo percepcionado.

${ }^{6}$ Concordamos, nesse ponto, com Kerbrat-Orecchioni (1996, p.41), para quem o contexto deveria ser visto menos como um entorno extralinguístico e muito mais como um "conjunto de representações que os interlocutores têm do contexto". Para a autora, em suma, o contexto seria "um conjunto de dados de natureza não objetiva, mas cognitiva", que se achariam interiorizados pelos interlocutores e mobilizáveis sempre que necessário no ato da enunciação (p. 42). 
estabelecimento do contexto, na organização dos turnos conversacionais e nos enquadres (socio)cognitivos por meio dos quais os indivíduos interpretam o mundo.

Entre outros elementos de compreensão do contexto interacional e do desenvolvimento do tópico, Marcuschi (2006) assinala, como vimos, a negociação, a construção ou o reconhecimento de um conhecimento e de um foco comum ("sintonia referencial"), as operações de enquadres cognitivos, entre eles os frames.

A noção de frame tem a ver, como já afirmava Fillmore nos anos 1980, com "um sistema de conceitos relacionados de tal forma que, para entender qualquer um deles, é necessário entender toda a estrutura em que se insere; quando uma coisa nesta estrutura é introduzida em um texto, ou em uma conversa, todas as outras são automaticamente disponibilizadas" (VEREZA, 2013, p. 114). Para o autor, lembremos, frame é um termo geral que diz respeito a todo um "conjunto de conceitos conhecidos na literatura como "esquema", "script", "cenário", "evento", "andaime ideacional", "modelo cognitivo" ou "teoria popular" (FILLMORE, 1982, p. 373). Cultural e experencialmente adquiridas e moduladas, tais cenas ou enquadres sociocognitivos atuam na maneira como compreendemos e atuamos no mundo.

Destaquemos, a propósito, algumas características das atuais abordagens interacionais e discursivas de frame que partem, de um modo ou de outro, da reflexão original de Fillmore:

(i) frames configuram-se em termos de "esquemas de conhecimento" que guiam e estruturam o uso da linguagem (CIENKI, 2007, p. 173), enquadram ou emolduram nossas experiências psicossociais; são, pois, projetivos, generalizantes, convencionais;

(ii) frames são uma forma de generalização e abstração de cenas e experiências convencionais; são, pois, estruturas conceptuais baseadas em esquematização (TOMASELLO, 2014, p. 12) e moduladas a partir de vários tipos de situações, eventos e categorias de objetos;

(iii) sendo os frames convencionais e episódicos, podem ser tomados como tipos de modelos de evento socioculturalmente compartilhados (VAN DIJK, 1992 [1988], p. 162);

(iv) frames são "dinâmicos" (CROFT; CRUSE, 2004). Em termos discursivos, essa dinâmica se deixa ver nas unidades lexicais, nas expressões referenciais (em especial, nas recategorizações), nas construções predicativas, nas tematizações de experiências, nas manipulações enunciativas de processos meta e de processos figurativos, na relação entre variáveis do contexto interacional situacional e social, nas características da estruturação da conversação, nas formas de categorização social realizadas pelos interagentes;

(v) frames são estratégicos, podendo ser recusados ou assumidos pelos interagentes (LAKOFF, 1987; 2004);

(vi) há diferentes graus de compartilhamento de um frame (VEREZA, 2013, p. 119).

(vii) à maneira do contexto situacional, o frame parece dizer respeito a "um estado de coisas que em parte está organizado a priori e em parte está associado a uma significação que emerge de sua própria organização” (MORATO, 2010b, p. 101). 
Abordagens sociocognitivas e discursivas de frame, por tomarem a dinâmica à la fois conceptual e interacional do fenômeno, acabam por constituir um interessante recurso analítico das atividades em curso nas práticas linguísticas. É no âmbito dessa concepção de fenômeno que procuramos em nosso estudo analisar o papel dos frames e da atividade referencial na organização do tópico discursivo.

\section{CONSTITUIÇÃO DO CORPUS E ASPECTOS METODOLÓGICOS}

O corpus com o qual trabalhamos constitui-se de quadros tópicos extraídos de cinco encontros semanais do CCA ocorridos no ano de 2010.

Em relação ao recorte e à análise do corpus, optamos por utilizar o modelo proposto por Jubran (2006) na identificação e delimitação dos tópicos discursivos; em relação aos frames, baseamo-nos na metodologia utilizada na Semântica de Frames, descrevendo os que não estão descritos na base lexicográfica Framenet e ampliando os contornos definicionais aqueles levantados no corpus em termos linguístico-textuais.

Para a transcrição dos quadros tópicos baseamo-nos em um sistema de transcrição multimodal (JEFFERSON, 1984; MONDADA, 2004; MARCUSCHI, 1987), a nosso ver apropriado para dar visibilidade aos fenômenos linguístico-interacionais.

Uma vez constituído o corpus da pesquisa a partir do estabelecimento de quadros tópicos extraídos das interações conversacionais desenvolvidas no CCA, passamos a verificar a plausibilidade empírica da principal hipótese de análise aventada no decurso da pesquisa, em parte decorrente da concepção de frame que abraçamos.

Considerando que a análise de qualquer interação requer atenção a vários processos verbais e não verbais e que, como afirma Gumperz (1982), "interagir é seguir e reconhecer pistas", perguntamo-nos quais seriam as "pistas" a serem levadas em conta para capturar o "pensamento do outro".

Passamos a observar em nossos dados elementos que permitem tratar analiticamente essa questão, como as construções referenciais (categorização, anafóricos, dêiticos, formulaicos etc.), os processos de natureza meta (metalinguísticos, metaenunciativos, metadiscursivos etc.), as semioses não verbais (gestualidade, direcionamento do olhar etc.), as inferências de diversas naturezas (textuais, contextuais, semânticas etc.).

Todos esses elementos, verbais e não verbais, como pudemos notar, atuam como "âncoras" textuais e sociocognitivas com função de centração e de organicidade (JUBRAN, 2006) $^{7}$ na atividade referencial, na mobilização de

\footnotetext{
${ }^{7}$ Como afirma Jubran (2006, p. 35): “A fim de particularizar a noção de tópico discursivo, o Grupo de Organização Textual-Interativa do Projeto de Gramática do Português Falado (PGPF) definiulhe duas propriedades: a de centração e a de organicidade". A primeira propriedade, fundamental para a referencialidade textual, abrange os traços de concernência, relevância e pontualização; a segunda, fundamental para a compreensão da organização tópica do texto falado ou escrito, "é manifestada por relações de interdependência tópica que se estabelecem simultaneamente em dois planos: no plano hierárquico, vertical, conforme as dependências de super ou subordenação entre tópicos que se implicam pelo grau de abrangência com que são tratados na interlocução; no plano linear, de acordo com as articulações intertópicas em termos de adjacência ou interposições de tópicos na linha do discurso (JUBRAN, 2006, p.36). Veremos, mais adiante, que a centração é altamente dependente dos processos que atuam ao nível da organicidade do tópico, o que assinala a estreita relação entre as duas propriedades na construção da topicalidade.
} 
frames, na contextualização dos sentidos, na progressão tópica, na organização conversacional (JUBRAN et al, 1992).

\section{EXEMPLIFICAÇÃO}

Nesta seção pretendemos ilustrar nosso empreendimento analítico por meio da observação de processos referenciais e de frames ativados em um quadro tópico extraído de um encontro do CCA ocorrido no dia 10 de junho de 2010. Trata-se de uma conversação cujo principal tópico versa sobre dificuldades de acesso lexical e as estratégias aventadas pelos interagentes para superá-las. No quadro tópico em questão, intitulado "Uso de estratégias para dificuldades de evocação", os participantes afásicos e não afásicos presentes elencam e descrevem suas dificuldades mais recorrentes de evocação (relacionadas à produção ou compreensão oral e escrita de palavras, textos, números), bem como levantam conjuntamente as estratégias de que lançam mão para contorná-las, como o uso de analogias, paráfrases, repetições.

A análise tópica desenvolveu-se a partir da (i) identificação e delimitação dos segmentos tópicos, isto é, das unidades discursivas que atualizam as propriedades do tópico, bem como da (ii) caracterização dos procedimentos pelos quais os segmentos tópicos se distribuem na linearidade discursiva e se inter-relacionam no plano hierárquico, segundo os graus de abrangência do assunto por eles recoberto.

A identificação dos frames ativados por meio de construções textuais (cadeias referenciais, encapsulamentos anafóricos, explicações, exemplificações) tomou como referência a base lexicográfica da FrameNet (ICSI-Berkeley/UFJF) ${ }^{8}$.

\subsection{Quadro tópico "Uso de estratégias para dificuldades de evocação" Participantes afásicos: RC, MN, SP, MG, LM, SI \\ Participantes não afásicos: HM e EG (pesquisadoras)}

As dificuldades de evocação estão na base do movimento inicial desse quadro tópico que trata, ainda, do levantamento de estratégias (mnemônicas, analógicas etc.) para superá-las. Isso acontece, por exemplo, no desenvolvimento dos tópicos "Dificuldade em evocar a distinção diet/light" (segmento tópico 1) e "Estratégia associativa para evocar a distinção diet/light" (segmento tópico 2); "Dificuldade em evocar números" (segmento tópico 16) e "Estratégias de repetição para evocar números de telefones" (segmento tópico 18); "Dificuldade em compreender a leitura" (segmento tópico 21) e "Estratégia associativa para compreender a leitura" (segmento 22).

No início do referido encontro, um dos participantes afásicos, LM, menciona sua dificuldade para lembrar a diferença entre produtos diet e light. A partir desse

\footnotetext{
${ }^{8}$ https://ramenet.icsi.berkeley.edu/fndrupal/; http://www.ufjf.br/framenetbr/projetos/frames-econstrucoes/
} 
momento, os participantes do grupo começam a abordar outras dificuldades de evocação e as estratégias de que se servem para superá-las. Ao fornecer exemplos de estratégias para se lembrar ou superar dificuldades de evocação, a participante não afásica HM leva o grupo a refletir sobre o fato de que tais dificuldades não se devem apenas ao contexto afásico, mas fazem parte do cotidiano de todas as pessoas, afásicas ou não. Ela também afirma que tanto afásicos, quanto não afásicos se servem de estratégias variadas para ajudar o processo de memorização e de evocação das palavras e informações (como associação entre palavras e frases, uso de símbolos, fórmulas, analogias etc.).

No esquema abaixo encontra-se representado o quadro tópico em questão, "Uso de estratégias para dificuldades de evocação". Dado o escopo deste artigo, focalizaremos um dos segmentos do tópico principal ("Uso de estratégias para dificuldades de evocação"), intitulado "Dificuldade em evocar a distinção diet/ light”, subordinado ao tópico "Dificuldades de evocação do grupo”.

\section{Esquema 1: Organização hierárquica do quadro tópico}

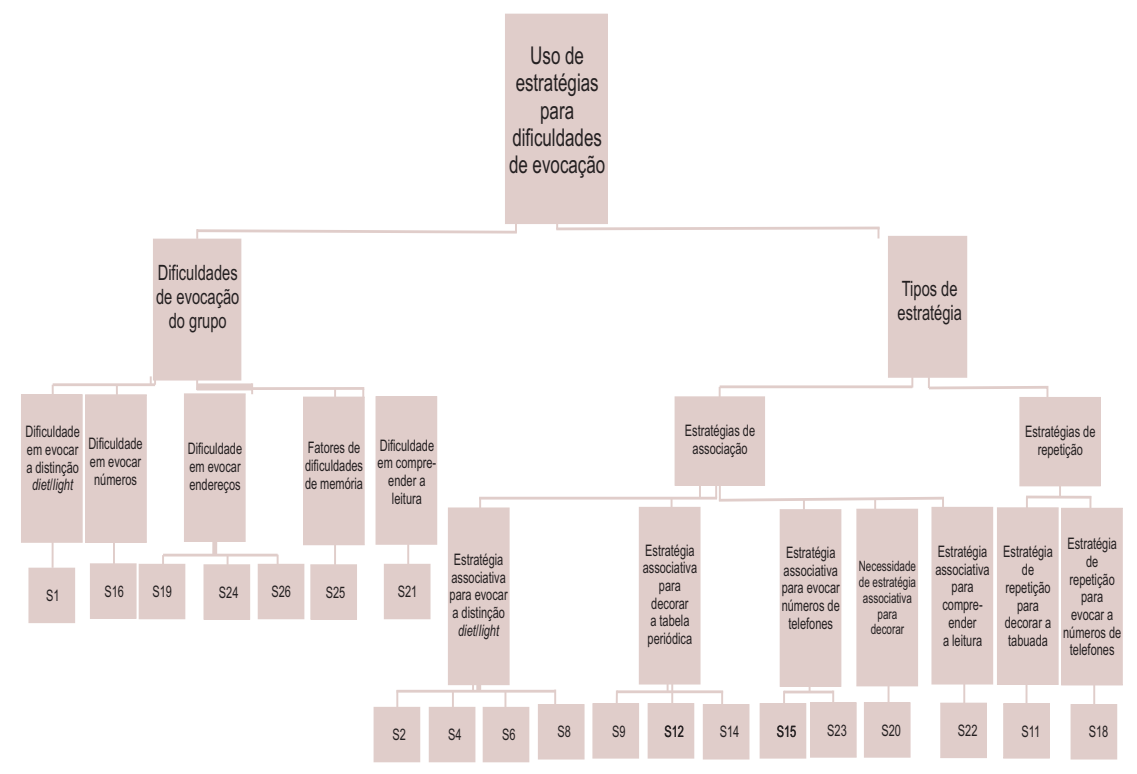

No desenvolvimento inicial do tópico "Dificuldades de evocação do grupo" observamos uma disputa interpretativa entre as participantes não afásicas HM e EG para referendar os sentidos que podem ser atribuídos à fala do participante afásico LM quando este afirma, a respeito da distinção diet e light: [eu]...passa um...um dia dois dia...eu já...esqueço.

LM confirma no decurso da conversação que sua dificuldade está relacionada ao desconhecimento da diferença conceitual entre diet e light e não propriamente à lembrança ou evocação (mnêmica) de alimentos classificados como diet ou light. 
$\mathrm{O}$ desconhecimento da diferença entre os termos diet (termo da língua inglesa que remete à dieta) e light (termo da língua inglesa que remete à leve), assinalese, não pode ser creditado a problemas de natureza afásica; de fato, muitos são os que, não sendo afásicos, desconhecem a diferença entre alimentos isentos de determinados nutrientes (diet) e alimentos de baixo ou reduzido valor energético (light). A falta de clareza na distinção entre ambos provavelmente justifique a modalização realizada pela participante afásica $\mathrm{MG}$ ao comentar, seguida de risos gerais, a relação entre os dois tipos de produto alimentício: é quase a mesma coisa. Outro participante afásico, RC, em segmento tópico posterior, agrega um comentário sobre essa indistinção, afirmando que em sua casa são usados tanto produtos light, quanto diet: tanto faz.

Esse início é importante para as tomadas de decisão que se observam sobre estratégias associativas de lembrança e de enfrentamento de dificuldades de evocação. O levantamento das características e finalidades do consumo de um ou de outro tipo de produto atua na distinção e evocação dos termos diet e light. Vejamos, a propósito, os exemplos abaixo:

\section{Segmento tópico 2: Estratégia associativa para evocar a distinção diet/light \\ HM então a gordura o que que ela é/ \\ LM pesada \\ HM pesada... então o produto light é o produto leve com menos gordura... tenta fazer essas associações pra ver se ajuda a guardar melhor $(\ldots)$}

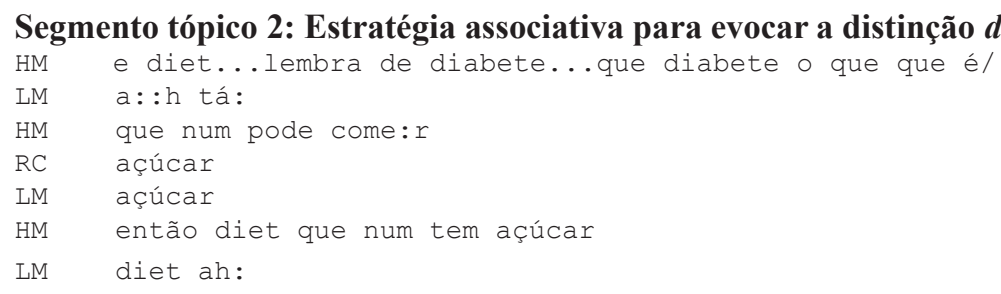

No desenvolvimento do tópico "Estratégia associativa para evocar a distinção diet/light”, observamos a alternância deste com o tópico inserido “Tipos de alimentos consumidos pelo grupo". Esse tópico inserido está ligado à intervenção inicial da pesquisadora EG que, frente à dificuldade mencionada por LM, sugere a estratégia de trazer à mente produtos consumidos ou vistos no supermercado que se diferenciam pelo seu tipo - diet ou light. Assim, apesar de a interpretação de HM sobre a fala de LM ter sido referendada pelo próprio participante afásico e de HM ter dado início, a partir dessa confirmação, ao tópico "Estratégia associativa para evocar a distinção diet/light”, há também, de forma paralela, o desenvolvimento de um tópico inserido, ligado à sugestão apresentada por EG.

O tópico "Tipos de alimentos consumidos pelo grupo", apesar de se relacionar com a diferença entre produtos diet e light, não se subordina diretamente ao supertópico "Uso de estratégias para dificuldades de evocação", pois não 
trata do uso de estratégias para ajudar ou ativar o processo de memorização e de evocação. Por não se subordinar ao supertópico em desenvolvimento, ele deve ser considerado um tópico inserido na conversação com finalidades coesivas.

Com efeito, a remissão ao desconhecimento da diferença entre diet e ligth provoca relatos e comentários dos interagentes sobre tipos de alimentos que consomem, constituindo um tópico ("Tipos de alimentos consumidos pelo grupo") que funciona como elemento coesivo em relação ao tópico principal na medida em que fornece elementos avaliativos que ancoram decisões estratégicas (que partem tanto da distinção entre os dois produtos -" $D$ de diabete e $L$ de leve", como sugere HM - , quanto as que partem da indistinção - como indicam os participantes afásicos $\mathrm{MG}$ e RC - uma vez que ambos diriam respeito, igualmente, a alimentos considerados saudáveis). Os interagentes, desa forma, levam em consideração informações, pressupostos e opiniões de que dispõem ou que são construídos localmente na conversação, relacionam elementos dos subtópicos e tópicos inseridos com o tópico principal (fornecendo exemplos e aventando estratégias para superar dificuldades de evocação), cooperam entre si com vistas à continuidade tópica e levam em conta o enquadre interativo no qual estão imersos.

\subsection{Processos referenciais e frames atuantes na centração e organicidade tópica}

Ao observarmos a organização hierárquica e linear do quadro tópico "Uso de estratégias para dificuldades de evocação", podemos constatar que a sua gestão, em termos de sua organicidade, está relacionada principalmente a processos de natureza sociocognitiva como inferências, verificação de common ground, checagem de informação, processos metadiscursivos.

Podemos constatar na Tabela 1 que, em termos quantitativos, os recursos metadiscursivos constituem o fenômeno mais atuante na organicidade tópica. Porém, se considerarmos que a checagem de informação e a construção de common ground encontram-se inter-relacionados na verificação de conhecimentos compartilhados entre os interagentes, podemos afirmar que tais processos são também fundamentais para a continuidade tópica. 
Tabela 1: Processos relativos à propriedade de organicidade tópica

\begin{tabular}{|c|c|c|c|}
\hline \multirow[t]{2}{*}{ Processos } & \multicolumn{2}{|r|}{ Funcionamento } & $\begin{array}{l}\text { Segmento } \\
\text { Tópico }\end{array}$ \\
\hline & $\begin{array}{l}\text { Verificação de } \\
\text { common ground }\end{array}$ & $\begin{array}{l}\text { Pergunta sobre o conhecimento dos } \\
\text { participantes quanto à origem e ao } \\
\text { significado em português das palavras } \\
\text { diet e light }\end{array}$ & 2 \\
\hline \multirow{4}{*}{$\begin{array}{l}\text { Relativos } \\
\text { ao common } \\
\text { ground }\end{array}$} & $\begin{array}{l}\text { Construção de } \\
\text { common ground }\end{array}$ & $\begin{array}{l}\text { Explicação sobre a estratégia de } \\
\text { associação para evocar a distinção diet/ } \\
\text { light }\end{array}$ & 2 \\
\hline & $\begin{array}{l}\text { Construção de } \\
\text { common ground }\end{array}$ & $\begin{array}{l}\text { Explicação sobre o tópico em } \\
\text { relevância na interação }\end{array}$ & 8 \\
\hline & Checagem & $\begin{array}{l}\text { Pergunta de checagem para verificar } \\
\text { a validade da compreensão sobre o } \\
\text { conceito de diet }\end{array}$ & 6 \\
\hline & Checagem & $\begin{array}{l}\text { Pergunta de checagem para verificar a } \\
\text { compreensão do interlocutor sobre o } \\
\text { conceito de light }\end{array}$ & 6 \\
\hline \multirow{3}{*}{$\begin{array}{c}\text { Recursos de } \\
\text { natureza meta }\end{array}$} & $\begin{array}{l}\text { Com enfoque no } \\
\text { uso do código } \\
\text { linguístico }\end{array}$ & $\begin{array}{l}\text { Sinalização da associação entre } \\
\text { palavras por meio do foco em seus } \\
\text { significados e em suas aliterações }\end{array}$ & 2 \\
\hline & $\begin{array}{l}\text { Com enfoque na } \\
\text { enunciação }\end{array}$ & $\begin{array}{l}\text { Retomada de tópico após inserção } \\
\text { tópica }\end{array}$ & 8 \\
\hline & $\begin{array}{l}\text { Com enfoque na } \\
\text { formulação do } \\
\text { discurso }\end{array}$ & $\begin{array}{l}\text { Progressão tópica e organização da } \\
\text { porção textual por meio de pergunta } \\
\text { retórica }\end{array}$ & 8 \\
\hline
\end{tabular}

Pudemos observar na análise do quadro tópico em questão que a centração se constrói especialmente a partir de determinados processos referenciais (anáforas diretas, indiretas, encapsuladoras e predicações) e reformuladores (paráfrases e repetições). Vejamos, a propósito, na Tabela 2, quais os processos referenciais e textuais mais produtivos que atuam na centração desse quadro tópico. 


\section{Tabela 2: Processos relativos à propriedade de centração tópica}

\begin{tabular}{|c|c|c|}
\hline \multirow[t]{4}{*}{ Processo } & Funcionamento & $\begin{array}{l}\text { Segmento } \\
\text { Tópico }\end{array}$ \\
\hline & $\begin{array}{l}\text { Anafóricos diretos do referente associação, responsáveis } \\
\text { por manter o referente em foco. }\end{array}$ & 6 e 8 \\
\hline & $\begin{array}{l}\text { Anafóricos diretos do referente light, que permitem a sua } \\
\text { manutenção e atribuição de novas propriedades a ele. }\end{array}$ & 2 \\
\hline & $\begin{array}{l}\text { Anafóricos diretos do referente guardar, responsáveis } \\
\text { por manter o referente em foco. }\end{array}$ & 2 e 8 \\
\hline \multirow[t]{4}{*}{ Categorizações } & $\begin{array}{l}\text { Anafóricos indiretos do referente associação, que } \\
\text { expressam a fórmula associativa proposta para a } \\
\text { memorização da distinção entre }\end{array}$ & 2 \\
\hline & $\begin{array}{l}\text { Anafóricos indiretos do referente light, que fornecem } \\
\text { as "pistas" para a realização do raciocínio associativo } \\
\text { proposto. }\end{array}$ & 2 \\
\hline & $\begin{array}{l}\text { Anafóricos indiretos do referente "diet", que fornecem } \\
\text { as "pistas" para a realização do raciocínio associativo } \\
\text { proposto. }\end{array}$ & 2 \\
\hline & $\begin{array}{l}\text { Atribuição de propriedades ao referente light que } \\
\text { contribuem para a definição do conceito a ser evocado } \\
\text { e, consequentemente, para a explicação da estratégia } \\
\text { associativa proposta. }\end{array}$ & 2 e 6 \\
\hline \multirow[t]{2}{*}{ Predicações } & $\begin{array}{l}\text { Atribuição de propriedades ao referente diet que } \\
\text { contribuem para a definição do conceito a ser evocado e, } \\
\text { consequentemente, para a } \\
\text { explicação da estratégia associativa proposta, tópico do } \\
\text { excerto em questão. }\end{array}$ & 2 e 6 \\
\hline & $\begin{array}{l}\text { Atribuição da ação de lembrar/guardar ao participante } \\
\text { LM, o que contribui para a manutenção e construção do } \\
\text { referente guardar, introduzido previamente no segmento } \\
\text { tópico } 2 \text {. }\end{array}$ & 4 \\
\hline \multirow{3}{*}{$\begin{array}{l}\text { Encapsulamentos } \\
\text { anafóricos }\end{array}$} & $\begin{array}{l}\text { Introdução catafórica do referente associação, } \\
\text { desenvolvido nos segmentos textuais subsequentes. }\end{array}$ & 2 \\
\hline & $\begin{array}{l}\text { Remissão aos segmentos textuais desenvolvidos } \\
\text { anteriormente, sobre a estratégia associativa. }\end{array}$ & 2 \\
\hline & $\begin{array}{l}\text { Paráfrase de generalização para proposição do raciocínio } \\
\text { de base associativa para o enfrentamento de dificuldades } \\
\text { de evocação de outros conceitos e palavras. }\end{array}$ & 6 \\
\hline Parafrases & $\begin{array}{l}\text { Paráfrase especificadora para explicitação do tópico em } \\
\text { andamento para uma participante da interação, a fim de } \\
\text { garantir sua expansão. }\end{array}$ & 8 \\
\hline
\end{tabular}


Repetições

Repetições de função coesiva para a construção dos conceitos diet e light a serem evocados e da estratégia proposta para isso.

Como afirmamos anteriormente, quando LM introduz o tópico sobre sua dificuldade de lembrar a diferença entre diet e light, há uma negociação entre as participantes não afásicas HM e EG no sentido de interpretar a natureza da dificuldade relatada por ele, cognitiva (mnêmica) ou linguística (referencial). Certamente, essa negociação tem por base distintas concepções ou escopos do termo afasia. O frame Afasia (ver, abaixo, a tabela 3) é fundamental nesse momento, pois mobiliza determinadas inferências e construções referenciais - algo importante para a forma pela qual se dá a progressão do tópico. A referida negociação definirá não apenas a natureza da dificuldade aludida por LM, como o tipo de estratégia a ele sugerida.

Vejamos, a propósito, quais os frames que atuam na continuidade e na gestão do quadro tópico "Uso de estratégias para dificuldades de evocação”. Na tabela abaixo, identificamos os frames que atuam como âncora textual e cognitiva (KAMP, 2011; SCHWARZ, 2000) com base na representação de experiências pessoais e sociais dos interagentes. Parte integrante da cena referencial construída na progressão tópica, essas estruturas de conhecimento (ENSINK; SAUER, 2003) têm por função, principalmente, orientar a significação, estabelecer ou explicitar propósitos discursivos, ponderar a relação entre informação dada e nova.

Tabela 3: Descrição dos frames mobilizados no quadro tópico

\begin{tabular}{l|l}
\multicolumn{1}{c|}{ Frames } & \multicolumn{1}{c|}{ Descrição e elementos de frames } \\
$\begin{array}{l}\text { TERAPIA (baseado no frame } \\
\text { MEDICAL_INTERVENTION - } \\
\text { FrameNet) }\end{array}$ & $\begin{array}{l}\text { Intervenções procedurais são usadas em uma } \\
\text { pessoa para tentar aliviar uma condição médica. }\end{array}$ \\
$\begin{array}{l}\text { MEMÓRIA (baseado no frame } \\
\text { MEMORY } \\
\text { - FrameNet) }\end{array}$ & $\begin{array}{l}\text { Esse frame consiste em cognoscentes lembrando } \\
\text { e esquecendo um conteúdo mental. }\end{array}$ \\
$\begin{array}{l}\text { MEIO (baseado no frame MEIO - } \\
\text { FrameNet Brasil) }\end{array}$ & $\begin{array}{l}\text { Um agente faz uso de um meio - tanto uma ação } \\
\text { ou um sistema de entidades necessário para a } \\
\text { ação - a fim de se obter a finalidade. }\end{array}$ \\
\hline $\begin{array}{l}\text { SITUAÇÃO DE DIFICULDADE } \\
\text { (baseado no frame } \\
\text { PREDICAMENT - FrameNet) }\end{array}$ & $\begin{array}{l}\text { Um experienciador está em uma situação } \\
\text { de dificuldade, cuja causa também pode ser } \\
\text { expressa. }\end{array}$ \\
$\begin{array}{l}\text { ALIMENTAÇÃO SAUDÁVEL } \\
\text { (baseado no frame CUSTOM - } \\
\text { FrameNet) }\end{array}$ & $\begin{array}{l}\text { Um comportamento alimentar saudável é } \\
\text { classificado como estabilizado para uma pessoa } \\
\text { ou grupo. }\end{array}$ \\
\hline
\end{tabular}


Esse frame nomeia uma condição médica que afeta a

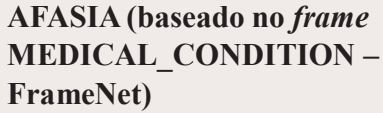

linguagem de pacientes. Ela é geralmente descrita por seus sintomas linguísticos, condições que a acompanham (parafasia, anomia, jargonofasia, hemiparesia etc.) e por ser decorrente de lesão cerebral. Podemos encontrar concepções distintas de afasia: linguística, cognitiva, neuropatológica etc.

Os frames identificados como mais relevantes e proeminentes no quadro tópico aqui focalizado foram: (i) Terapia; (ii) Memória; (iii) Meio; (iv) Situação de Dificuldade; (v) Alimentação Saudável; (vi) Afasia. Os frames mais incidentes no quadro tópico "Uso de estratégias para dificuldades de evocação" foram: Meio, Terapia e Memória. Vejamos na tabela abaixo a atuação desses frames:

\section{Tabela 4: Frames mobilizados no quadro tópico "Uso de estratégias para dificuldades de evocação"}

\begin{tabular}{|c|c|c|c|c|c|c|c|}
\hline \multirow{2}{*}{$\begin{array}{l}\text { Tópicos } \\
\text { Frames }\end{array}$} & \multicolumn{4}{|c|}{ "Dificuldades de evocação do grupo" } & \multicolumn{3}{|c|}{$\begin{array}{c}\text { "Tipos de } \\
\text { Estratégias" }\end{array}$} \\
\hline & $\begin{array}{l}\text { Evocar a } \\
\text { distinção } \\
\text { diet/ light }\end{array}$ & $\begin{array}{l}\text { Evocar } \\
\text { números }\end{array}$ & $\begin{array}{c}\text { Evocar } \\
\text { endereços }\end{array}$ & $\begin{array}{c}\text { Compre- } \\
\text { ender a } \\
\text { leitura }\end{array}$ & $\begin{array}{l}\text { Associa- } \\
\text { ção }\end{array}$ & Repetição & Total \\
\hline Meio & 1 & 1 & 1 & 1 & 7 & 2 & 13 \\
\hline Terapia & 1 & 0 & 1 & 0 & 8 & 2 & 12 \\
\hline Memória & 1 & 1 & 1 & 0 & 6 & 2 & 11 \\
\hline $\begin{array}{l}\text { Situação de } \\
\text { dificuldade }\end{array}$ & 1 & 1 & 2 & 1 & 1 & 0 & 6 \\
\hline $\begin{array}{c}\text { Alimentação } \\
\text { saudável }\end{array}$ & 1 & 0 & 0 & 0 & 1 & 0 & 2 \\
\hline Afasia & 1 & 0 & 0 & 0 & 0 & 0 & 1 \\
\hline Ativ./tópico & 6 & 3 & 5 & 2 & 23 & 6 & 45 \\
\hline
\end{tabular}

Observamos que esses frames podem agir tanto em conjunto no desenvolvimento tópico, ocorrência mais frequente em nossos dados, quanto de forma mais isolada ou pontual (tal como ocorre com o frame Alimentação Saudável).

Observamos, ainda, que são também os frames Terapia, Memória e Meio que agem de uma forma mais entrelaçada (VEREZA, 2013), particularmente no subtópico "Tipos de estratégias". Uma das consequências do entrelaçamento 
mais forte entre esses frames é um maior desenvolvimento desse subtópico, que apresenta mais segmentos tópicos e se mostra relevante para a coesividade comunicacional.

Vejamos, a propósito, um exemplo do entrelaçamento dos frames Meio e Memória atuando no desenvolvimento do tópico "Estratégia associativa para evocar a distinção diet/light”:

\section{Segmento tópico 6}

HM agora pro- assim... sempre que tiver dificuldade pra guardar... vocês fazem esse tipo de coisa/ quando tem quando tem alguma coisa que tá difícil de guardar... de fazer associações/

Quanto à atuação de frames na centração tópica, observamos que houve tanto ativação isolada, quanto entrelaçamento entre eles, como na atuação coordenada dos frames Memória, Alimentação Saudável e Afasia no desenvolvimento do tópico "Dificuldade em evocar distinção diet/light". O frame Alimentação Saudável é o mais atuante na centração desse tópico, com base em anafóricos, encapsuladores, repetições, predicações e paráfrases. A remissão aos comportamentos alimentares tidos como saudáveis parece ser condição para a manutenção do tópico.

No tópico "Dificuldade em compreender a leitura", em cuja centração atuam os frames Meio, Afasia e Situação de Dificuldade, observamos que os interagentes atribuem à afasia as dificuldades associadas à compreensão da leitura, e não a outros fatores como experiência de letramento ou mesmo grau de escolaridade.

Nos tópicos "Estratégias de associação" e "Estratégias de repetição" é o frame Memória que orienta a significação e a continuidade tópica, indicando que os interagentes interpretam esses processos - estratégias de associação e de repetição - como atos essencialmente mnêmicos. Não é à toa que o participante afásico LM leva a mão à cabeça ao dizer agora eu vou ver se eu..., enunciado interrompido pela participante afásica MG que o completa: lembra.

Já nos tópicos "Dificuldade em evocar números" e "Dificuldade em evocar endereços" são os frames Memória e Situação de Dificuldade que entrelaçam e conectam informações e conhecimentos tidos como relevantes para a compreensão e a superação dos problemas nominativos apresentados pelos afásicos. Vejamos, abaixo alguns exemplos:

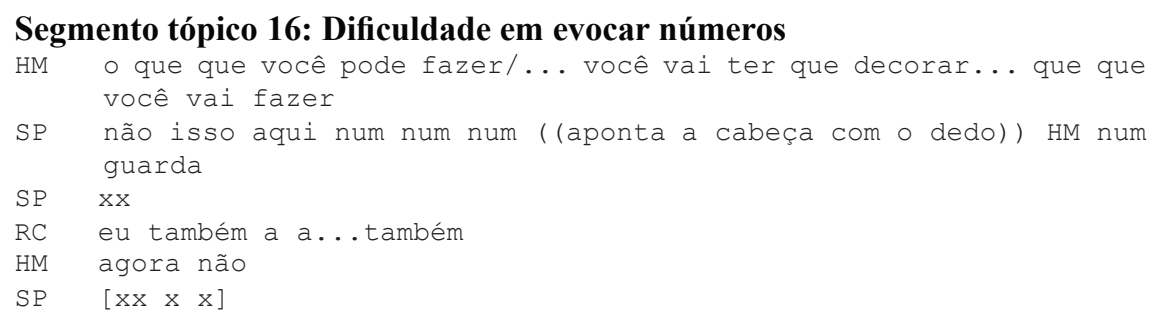




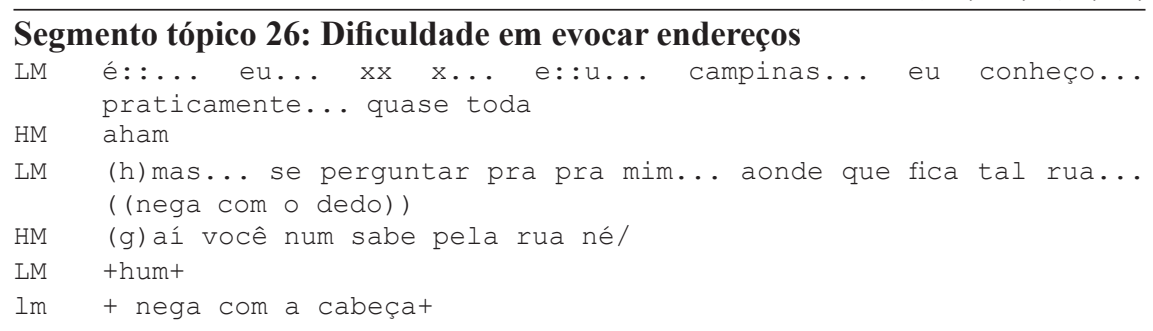

Podemos dizer, em suma, que os frames ativados e construídos no desenvolvimento desse quadro tópico mostram-se essenciais à construção da coesividade comunicacional, atuando tanto nos processos de centração (por exemplo, na perspectivação dos processos referenciais, nas formas metadiscursivas e nas atividades de reformulação e reparo), quanto na organicidade (por exemplo, na sedimentação de common ground, na contextualização da cena referencial e na evocação de conhecimentos e experiências).

Processos referenciais e frames mobilizados pelos interagentes no quadro tópico aqui analisado trazem à tona a questão do escopo do termo afasia (cuja dificuldade nominativa tem sido reportada tanto a um domínio mental - uma alteração da memória, por exemplo -, quanto a um domínio linguístico - uma alteração do processamento linguístico, fonológico ou lexical, por exemplo). Trazem também à tona a caracterização do enquadre interativo como situação terapêutica, num sentido largo.

\section{GENERALIZAÇÕES DOS RESULTADOS DA PESQUISA}

Elencamos abaixo, em termos gerais, os principais resultados a que chegamos em nossa pesquisa:

(i) não apenas o frame organiza o tópico, também a dinâmica interacional atua na progressão tópica;

(ii) os participantes do CCA realizam um percurso textual sociocognitivamente ancorado: em construções referenciais, em processos de centração e de organicidade inter e intratópica, em frames localmente ativados e construídos.

(iii) o conjunto de frames ativados e mobilizados nas interações conversacionais, como as que ocorrem no CCA, assinala a natureza colaborativa, contextual e multimodal da atividade referencial. Esses frames são desenvolvidos por meio da mobilização de expressões linguísticas e da emergência de processos inferenciais, contextuais e multissemióticos (risos, expressão corporal, gestos, dêiticos espaciais, direcionamento do olhar etc.);

(iv) é possível identificar fenômenos referenciais "incorporadores" (isto é, que incorporam de maneira mais ou menos explícita a perspectiva do outro) tanto na centração, quanto na organicidade tópica. As informações condensadas no frame 
jogam luzes sobre o referente ou a construção referencial em curso e são obtidas por meio de algum tipo de relação contextual com o tópico em desenvolvimento;

(v) o frame funciona como uma "âncora cognitiva" (MARCUSCHI, 2005; SCHWARZ, 2000) para a atividade referencial. Nos tópicos que constituem o corpus, às vezes essa ancoragem (como os variados tipos de conhecimento dispostos na conversação, por exemplo) é mais facilmente reconhecida e compartilhada; às vezes, ela é mais ou menos comum (portanto, um trabalho de explicitação pode ser necessário);

(vi) riscos para a falta de coesividade comunicacional não se devem ou são associados apenas à afasia (pois são também observados na linguagem em uso, não sendo de forma alguma patológicos): a falta de elementos atuantes na coesividade comunicacional ou a não ativação conjunta de frames e de processos que atuam na construção referencial podem em quaisquer contextos - afásicos e não afásicos - interferir na progressão tópica e na coerência comunicacional;

(vii) o aspecto off topic atribuído à fala afásica não elimina o caráter reflexivo da linguagem e da interação, uma vez que os falantes afásicos não deixam de proceder, em face de dificuldades nominativas, a reparos, reformulações, promptings orais e gestuais etc.;

(viii) dados como os por nós observados constituem evidência empírica em defesa da hipótese de que os enquadres sociocognitivos (como os frames, dentre outros) são uma hipótese cognitiva para a referenciação, sendo o desenvolvimento tópico e a coesão comunicacional dois indícios empíricos que sustentam tal postulação.

\section{PALAVRAS FINAIS}

Estudos sobre a linguagem e a cognição em contexto ou em uso fortalecem o pressuposto de que as práticas linguísticas e interacionais são um locus de grande importância para a observação de uma relação mutuamente constitutiva entre conceptualização e interação.

No âmbito desse pressuposto, a análise do papel dos frames na organização e na progressão tópica mostra-se capaz de fornecer detalhes sobre essa relação, passível de ser observada no interior do modelo textual-interativo de tópico discursivo aqui adotado (JUBRAN, 2006), que parte de uma estreita relação entre texto e contexto.

Tal relação se deixa ver de forma interessante na conversação com afásicos e salienta, em virtude dos fenômenos neurolinguísticos associados à afasia, o caráter sociocognitivo dos elementos linguístico-interacionais em jogo na estruturação e no desenvolvimento do tópico discursivo.

Os conceitos e os referenciais com os quais lidamos na pesquisa são normalmente construídos com base em dados de linguagem de indivíduos sem comprometimento neurológico. Estendê-los para dados de afasia, além de aprofundar o conhecimento sobre esse tipo de dificuldade de linguagem 
possibilita, entre outras coisas, testar seu alcance explicativo para ambientes de funcionamento linguístico-cognitivo não patológico.

\section{REFERÊNCIAS BIBLIOGRÁFICAS}

CIENKI, A. Frames. Idealized cognitive models and domains. In: GEERAERTS, D.; CUYCKENS, H. (Eds.). The Oxford handbook of cognitive linguistics. Oxford: Oxford University Press, 2007.

CROFT, W; CRUSE, D. A. Cognitive Linguistics. Cambridge: Cambridge University Press, 2004.

ENSINK, T.; SAUER, C. Social-functional and cognitive approaches to discourse interpretation: the role of frame and perspective. In: Framing and perspectivising in discourse. Amsterdam/ Philadelphia: John Benjamins Publishing Company, 2003, p.1-22.

FILLMORE, C. J. Frame semantics. Linguistics in the morning calm: selected papers from SICOL-1981 (The linguistic society of Korea). Seoul: Hanshin Publishing Company, 1982.

GOFFMAN, E. Interaction ritual: Essays in face to face behavior. New York, 1967. GUMPERZ, J. J. Discourse strategies. Cambridge: Cambridge University Press, 1982.

HAMILTON, H. E. Conversations with an Alzheimer's patient. Cambridge University Press, 1994.

JAKOBSON, R. Dois aspectos da linguagem e dois tipos de afasia. In: Linguística e Comunicação. São Paulo: Cultrix, 1981 [1954].

JEFFERSON, G. Transcription notation. In: ATKINSON, J.; HERITAGE, J. (Eds). Structures of social interaction. New York: Cambridge University Press, 1984. JUBRAN, C.C.A.S. Revisitando a noção de tópico discursivo. Cadernos de Estudos Linguísticos, n. 48(1), Campinas, 2006, p. 33-41.

JEFFERSON, G.; et al. Organização tópica da conversação. In: ILARI, R. (Org.). Gramática do Português Falado. Campinas: Editora da Unicamp, v. II: Níveis de análise linguística, 1992, p. 357-439.

JUBRAN, C.C.A.S. Revisitando a noção de tópico discursivo. Cadernos de Estudos Linguísticos, n. 48(1), Campinas, 2006, p. 33-41.

JUBRAN, C.C.A.S.; et al. Organização tópica da conversação. In: ILARI, R. (Org.). Gramática do Português Falado. Campinas: Editora da Unicamp, v. II: Níveis de análise linguística, 1992, p. 357-439.

KAMP, H. Representing de se thoughts and their reports. Ms. Austin/Stuttgart, 2011. http:// nasslli2012.com/files/kamp 2011.pdf.

KERBRAT-ORECCHIONI, C. Texte et contexte. SCOLA - Sciences Cognitives, Linguistique \& Intelligence Artificielle 6, 1996, p. 40-59.

KOCH, I. G. V. Desvendando os segredos do texto. São Paulo: Cortez, 2002.

KOCH, I. G. Introdução à linguística textual. São Paulo: Martins Fontes, 2004.

KOCH, I. G.; MARCUSCHI, L. A. Processos de referenciação na produção discursiva. DELTA, v. 14: special issue. São Paulo, 1998, p. 169-190. 
KOCH, I. G.; PENNA, M. A. Construção/reconstrução de objetos-de-discurso: manutenção tópica e progressão textual. Caderno de Estudos Linguísticos, n. 48(1), 2006, p. 23-31.

LAKOFF, G. Women, fire, and dangerous things: what categories reveal about the mind. Chicago: The University of Chicago Press, 1987.

LAKOFF, G. Don't Think of an Elephant: know your values, frame the debate. Vermont: Chelsea Green Publishing, 2004.

MARCUSCHI, L. A. Análise da conversação. São Paulo: Ática, 1987.

MARCUSCHI, L. A.. Atos de referenciação na interação face a face. Cadernos de Estudos Linguísticos, v. 41, Campinas, 2001, p. 37-54.

MARCUSCHI, L. A.. Anáfora indireta: o barco textual e suas âncoras. In: KOCH, I. V.; MORATO, E. M.; BENTES, A. C. Referenciação e Discurso. São Paulo: Contexto, 2005, p. 53-101.

MARCUSCHI, L. A. Referenciação e progressão tópica: aspectos cognitivos e textuais. Cadernos de Estudos Linguísticos, n. 48(1), Campinas, 2006, p. 7-22.

MIRANDA, N. S.; BERNARDO, F. C. Frames, discurso e valores. Cadernos de Estudos Linguísticos, n. 55(1), p. 81-97. Campinas, 2013.

MONDADA, L. Temporalité, séquentialité et multimodalité au fondement de l'organisation de l'interaction: Le pointage comme pratique de prise du tour. In: FILLIETTAZ, L. (ed.). Les modèles du discours face au concept d'action. Cahiers de Linguistique Française, n. 26, 2004, p. 269-292.

MORATO, E.M. (org.). A semiologia das afasias: perspectivas linguísticas. São Paulo: Cortez, 2010a.

MORATO, E.M. A noção de frame no contexto neurolinguístico: o que ela é capaz de explicar? Cadernos de Letras da UFF. Dossiê: letras e cognição, n. 41, 2010b, p. 93-113.

MORATO, E.M. Neurolinguística. In: MUSSALIM, F. e BENTES, A.C. (orgs.). Introdução à Linguística: Domínios e fronteiras. São Paulo: Cortez, 2012 [2001]. pp. 167-200.

MORATO, E.M; BENTES, A. C. Frames em jogo na construção discursiva e interativa da referência. Cadernos de Estudos Linguísticos, n. 55(1), Campinas, 2013, p. 125-137.

SCHWARZ, M. Indirekte Anaphern in Texten. Tübingen: Niemeyer, 2000.

TOMASELLO, M. A natural history of human thinking. Cambridge: Harvard University Press, 2014.

VAN DIJK, T. Cognição, discurso e interação. São Paulo: Contexto, 1992 [1988].

VAN DIJK, T. Discurso e contexto: uma abordagem sociocognitiva. São Paulo: Contexto, 2012 [2008].

VEREZA, S. Entrelaçando frames: a construção do sentido metafórico na linguagem em uso. Cadernos de Estudos Linguísticos, n. 55(1), Campinas, 2013, p. 109-122.

Recebido: 22/07/2017

Aceito: 28/03/2017 